\title{
Assessment of COSMIC radio occultation retrieval product using global radiosonde data
}

\author{
B.-R. Wang ${ }^{1,2}$, X.-Y. Liu ${ }^{1}$, and J.-K. Wang ${ }^{1}$ \\ ${ }^{1}$ Dept. of Atmospheric and Oceanic Sciences, School of Physics, Peking University, Beijing, China \\ ${ }^{2}$ Aviation Meteorological Center, Air Traffic Management Bureau, Civil Aviation Administration of China, Beijing, China \\ Correspondence to: B.-R. Wang (markwangpk@gmail.com)
}

Received: 12 October 2012 - Published in Atmos. Meas. Tech. Discuss.: 23 November 2012

Revised: 20 March 2013 - Accepted: 30 March 2013 - Published: 29 April 2013

\begin{abstract}
The radio occultation retrieval product of the Constellation Observing System for Meteorology, Ionosphere, and Climate (COSMIC) Radio Occultation sounding system was verified using the global radiosonde data from 2007 to 2010. Samples of $4 \mathrm{yr}$ were used to collect quantities of data using much stricter matching criteria than previous studies to obtain more accurate results. The horizontal distance between the radiosonde station and the occultation event is within $100 \mathrm{~km}$, and the time window is $1 \mathrm{~h}$. The comparison was performed from $925 \mathrm{hPa}$ to $10 \mathrm{hPa}$. The results indicated that the COSMIC's temperature data agreed well with the radiosonde data. The global mean temperature bias was $-0.09 \mathrm{~K}$, with a standard deviation (SD) of $1.72 \mathrm{~K}$. According to the data filtration used in this paper, the mean specific humidity bias of $925-200 \mathrm{hPa}$ is $-0.012 \mathrm{~g} \mathrm{~kg}^{-1}$, with a SD of $0.666 \mathrm{~g} \mathrm{~kg}^{-1}$, and the mean relative error of water vapor pressure is about $33.3 \%$, with a SD of $107.5 \%$. The COSMIC quality control process failed to detect some of the abnormal extremely small humidity data which occurred frequently in subtropical zone. Despite the large relative error of water vapor pressure, the relative error of refractivity is small. This paper also provides a comparison of eight radiosonde types with COSMIC product. Because the retrieval product is affected by the background error which differed between different regions, the COSMIC retrieval product could be used as a benchmark if the precision requirement is not strict.
\end{abstract}

\section{Introduction}

COSMIC (Constellation Observation System for Meteorology, Ionosphere and Climate) is a GPS (Global Positioning System) radio occultation observation system. It consists of six identical microsatellites, and was launched successfully on 14 April 2006. GPS radio occultation observation has the advantage of near-global coverage, all-weather capability, high vertical resolution, high accuracy and self-calibration (Yunck et al., 2000; Steiner et al., 1999; Hajj et al., 2000; Kursinski et al., 2000).

The conventional method of observing high vertical resolution atmospheric pressure, temperature and humidity profiles is radiosonde sounding. It is a practical way to verify the COSMIC product data quality using radiosonde data. Assessment of GPS/MET indicated that radio occultation sounding provides good temperature accuracy, with bias of about $1 \mathrm{~K}$ from the lower troposphere to $40 \mathrm{~km}$ (Ware et al., 1996; Kursinski et al., 1996; Rocken et al., 1997). The studies in CHAMP (CHAllenging Minisatellite Payload) substantiated the results of GPS/MET, finding that radio occultation sounding has high accuracy from about $5 \mathrm{~km}$ to $25 \mathrm{~km}$ (Hajj et al., 2004; Kuo et al., 2004, 2005). Fu et al. (2009) assessed the COSMIC retrieved atmospheric profiles using Australian radiosonde station data for a period of 13 months. Sun et al. (2010) performed a comparison between COSMIC atmospheric profiles, refractivity profiles and radiosonde data for 18 months. He et al. (2009) compared the temperature profiles in the upper troposphere and lower stratosphere using radiosonde data. Ho et al. (2010) compared the specific humidity profile with radiosonde and ECMWF (European Centre for Medium-Range Weather Forecasts) analysis 
Table 1. Results of the temperature bias between COSMIC and radiosonde.

\begin{tabular}{llllllll}
\hline Authors & Region & Period & $\begin{array}{l}\text { Time } \\
\text { window }\end{array}$ & $\begin{array}{l}\text { Distance } \\
\text { limit }\end{array}$ & $\begin{array}{l}\text { Vertical } \\
\text { range }\end{array}$ & $\Delta T$ & SD $\Delta T$ \\
\hline Fu et al. (2009) & Australian & 13 months & $2 \mathrm{~h}$ & $100 \mathrm{~km}$ & $0-30 \mathrm{~km}$ & $-0.43 \mathrm{~K}$ & $1.53 \mathrm{~K}$ \\
Sun et al. (2010) & Global & 19 months & $6 \mathrm{~h}$ & $250 \mathrm{~km}$ & $850-200 \mathrm{hPa}$ & $<0.15 \mathrm{~K}$ & $1.5-2.0 \mathrm{~K}$ \\
He et al. (2009) & Global & 9 months & $2 \mathrm{~h}$ & $300 \mathrm{~km}$ & $12-25 \mathrm{~km}$ & $<0.5 \mathrm{~K}$ & $<2.0 \mathrm{~K}$ \\
\hline
\end{tabular}

for 4 months. Kishore et al. (2009) validated the first year of COSMIC temperature profiles using radiosonde data and operational stratospheric analysis data. These studies indicated that the results of COSMIC show a good agreement with radiosonde, especially the temperature data (see in Table 1). However, the collocation mismatch criteria were not strict due to the short data periods in those studies, or the comparisons were performed over restricted regions. Sun et al. (2010) reported that, in the troposphere $(850-200 \mathrm{hPa})$, the collocation mismatch impacts on the comparison standard deviation errors for temperature are $0.35 \mathrm{~K} / 3 \mathrm{~h}$ and $0.42 \mathrm{~K} / 100 \mathrm{~km}$, and for relative humidity are $3.3 \% / 3 \mathrm{~h}$ and $3.1 \% / 100 \mathrm{~km}$. In the present study, the assessment used data of $4 \mathrm{yr}$ from 2007 to 2010 . A longer period was used to collect sufficient samples to reduce the collocation mismatch. This comparison used the 1DVAR retrieval atmospheric occultation profiles wetPrf. The 1DVAR process separated the pressure, temperature and moisture contributions to refractivity, and the wetPrf data is atmospheric occultation profiles with moisture information included. The background used for the 1DVAR process is the ECMWF analysis data.

However, radiosonde itself suffers from measurement bias, such as radiation errors in temperature measurements and various errors in humidity (Luers and Eskridge, 1998; Wang et al., 2003; Wang and Zhang, 2008; Miloshevich et al., 2006). In addition to the sensor limitation, the radiosonde bias differs among stations due to geographical distribution and differences in radiosonde type (Soden and Lanzante, 1996; Christy and Norris, 2009). Besides, the comparison also included representativeness error. Radiosonde sounding is a point measurement, whereas radio occultation sounding actually measures the averages over finite volumes of the atmosphere (Kuo et al., 2004). Horizontal drift exists in both COSMIC and radiosonde profiles. A radiosonde balloon would drift because of the horizontal wind. Seidel et al. (2011) studied the global radiosonde balloon drift of 419 stations for the $2 \mathrm{yr}$ period from July 2007 to June 2009. The results indicated mean drift distances of $<20 \mathrm{~km}$ in the upper troposphere, and $<50 \mathrm{~km}$ in the lower stratosphere.

As the COSMIC data have the characters of global coverage and stability, although the 1DVAR retrieval product contains the information of background, it could be used as a benchmark to evaluate other observation data or model analysis (Sun et al., 2010; He et al., 2009; Ho et al., 2010). In this study, eight radiosonde types were chosen for the comparison to verify the relative accuracy between the COSMIC product and different radiosonde types. As the COSMIC product is also affected by the background error, we will discuss whether it is suitable to be used as a benchmark.

\section{Data and comparison method}

The COSMIC 1DVAR retrieval product wetPrf profiles and global radiosonde profiles from 2007 to 2010 were used for this comparison. The wetPrf data are atmospheric occultation profiles with moisture information included, and it includes the parameters of atmospheric pressure, geometric height, temperature, water vapor pressure, retrieved refractivity, etc. The observed refractivity profiles are also recorded in wetPrf data. The wetPrf profiles were downloaded from COSMIC Data Analysis and Archive Center (CDAAC). The data version was 2010.2640. The wetPrf data's altitude range is $0-40 \mathrm{~km}$ at $100 \mathrm{~m}$ vertical resolution. These data provided more than 1700 profiles globally per day on average from 2007 to 2010. The background used for 1DVAR process is the ECMWF analysis data. The temperature, pressure and moisture profiles generated from the ECMWF analysis are collocated with occultation profiles and are recorded in ecmPrf data. The ecmPrf data were also used for comparison. The radiosonde profiles were downloaded from the Integrated Global Radiosonde Archive (IGRA) which includes radiosonde and pilot balloon observations from over 1500 globally distributed stations.

The statistics of the COSMIC data from 2007 to 2010 indicated that the mean tangent point horizontal drift distance from altitude $1 \mathrm{~km}$ to $10 \mathrm{~km}$ was about $102 \mathrm{~km}$, and the drift distance from $1 \mathrm{~km}$ to $20 \mathrm{~km}$ was about $136 \mathrm{~km}$. In this study, the horizontal mismatch distance limit between the COSMIC occultation tangent point at the height of $10 \mathrm{~km}$ and the radiosonde station was set to $0.9^{\circ}$ in central angle difference, which is a horizontal distance of about $100 \mathrm{~km}$. The radiosonde data of 00:00 UTC and 12:00 were used, and the time window was $1 \mathrm{~h}$. A total of 737 radiosonde stations, whose distribution is shown in Fig. 1, were matched in this comparison. Eight kinds of radiosonde types were selected for comparison between different radiosonde types with COSMIC products. The stations using these radiosonde types are shown in different colors in Fig. 1.

The altitude range of wetPrf profiles was $0-40 \mathrm{~km}$ with high vertical resolution of $100 \mathrm{~m}$. However, the downloaded 


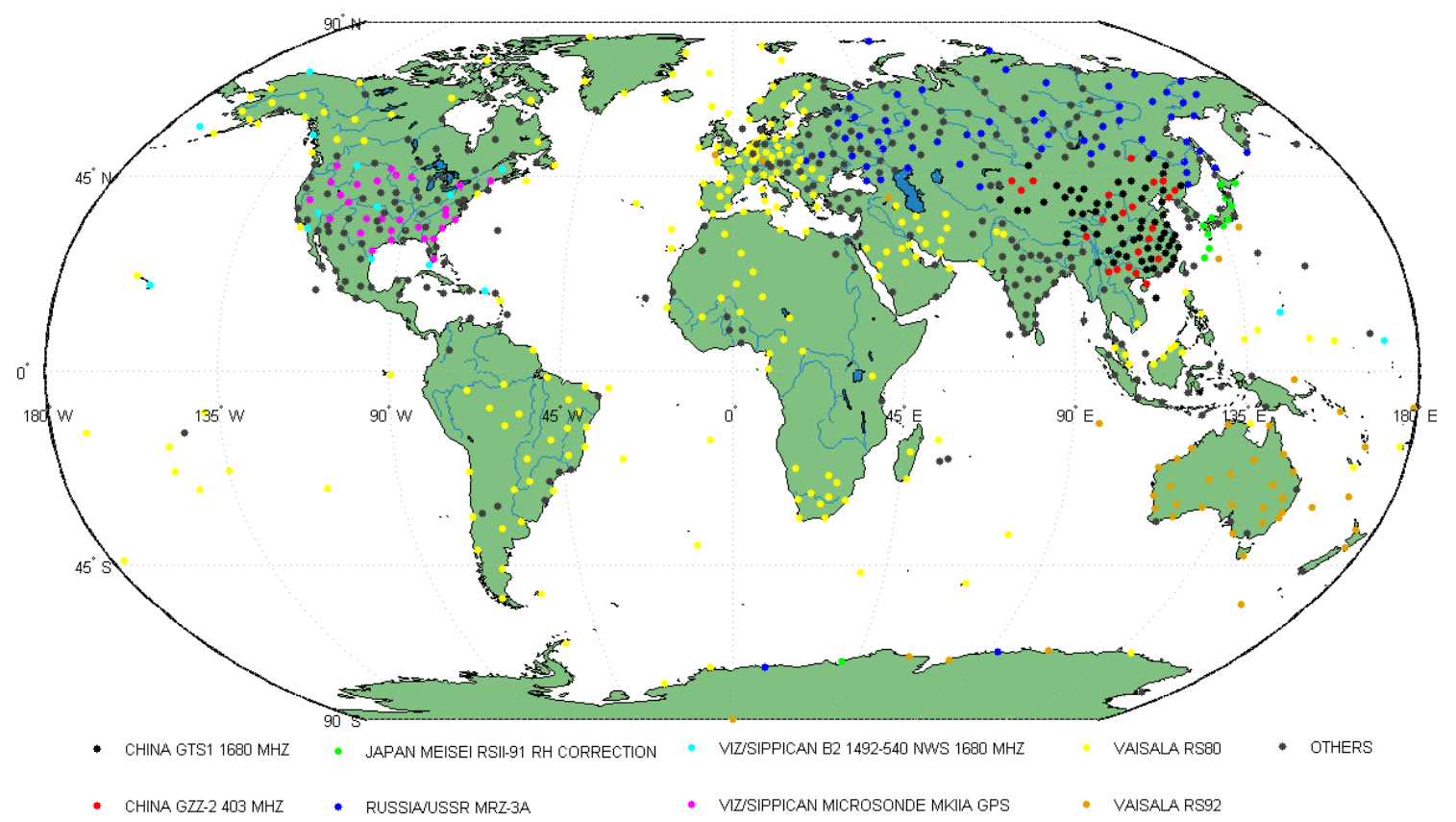

Fig. 1. Distributions of matched radiosonde stations.

radiosonde data had a much lower vertical resolution. To avoid errors due to interpolation of radiosonde profiles, the comparison was performed only on the standard pressure levels of the radiosonde profile. The standard pressure levels were from $1000 \mathrm{hPa}$ to $5 \mathrm{hPa}$, with a total of 18 layers. The numbers of radiosonde data points in $7 \mathrm{hPa}$ and $5 \mathrm{hPa}$ layers were small, and there were also insufficient wetPrf data points at the $1000 \mathrm{hPa}$ layer. Therefore, the comparison was performed at 15 pressure levels from $925 \mathrm{hPa}$ to $10 \mathrm{hPa}$. The water vapor pressure of radiosonde data was given by GoffGratch equation (Goff, 1957). The atmospheric refractivity of radiosonde was calculated using this function:

$N=77.6 \frac{P}{T}+3.73 \times 10^{5} \frac{P_{\mathrm{w}}}{T^{2}}$,

where $N$ is refractivity, $T$ is temperature in Kelvin, and $P$ and $P_{\mathrm{w}}$ are total air pressure and partial pressure of water vapor at $\mathrm{hPa}$, respectively.

The wetPrf data are recorded in altitude layers. It needs to be interpolated into pressure layers. The interpolation of wetPrf data was performed as

$\alpha=\frac{\ln P-\ln P_{2}}{\ln P_{1}-\ln P_{2}}, \beta=\frac{\ln P_{1}-\ln P}{\ln P_{1}-\ln P_{2}}$,

$T=\alpha \cdot T_{1}+\beta \cdot T_{2}$,

$q=\alpha \cdot q_{1}+\beta \cdot q_{2}$,

$P_{\mathrm{w}}=\exp \left(\alpha \cdot \ln \left(P_{\mathrm{w}_{1}}\right)+\beta \cdot \ln \left(P_{\mathrm{w}_{2}}\right)\right)$,
$N=\alpha \cdot N_{1}+\beta \cdot N_{2}$,

where $P$ is the pressure of the standard pressure level, subscript 1 and 2 stand for the parameters from wetPrf.

The interpolation was performed in a manner similar to linear interpolation of altitude. As the wetPrf data have high vertical resolution, the difference between different interpolation methods is small.

The comparison was performed in terms of temperature difference, $\Delta T$, specific humidity difference, $\Delta q$, relative error of water vapor pressure, RE $P_{\mathrm{w}}$, and relative error of refractivity, RE $N$, which are given by Eqs. (7) to (10), respectively.

$\Delta T=T_{\text {wet }} \operatorname{Pr} f-T_{\text {radiosonde }}$

$\Delta q=q_{\text {wet } \operatorname{Pr} f}-q_{\text {radiosonde }}$

$\operatorname{RE} P_{\mathrm{w}}=\left(P_{\mathrm{w}_{\mathrm{wet} \text { Pr } f}}-P_{\mathrm{w}_{\text {radiosonde }}}\right) / P_{\mathrm{w}_{\text {radiosonde }}}$

$\operatorname{RE} N=\left(N_{\text {wet } \operatorname{Pr} f}-N_{\text {radiosonde }}\right) / N_{\text {radiosonde }}$

If RE $P_{\mathrm{w}}>+900 \%$ or RE $P_{\mathrm{w}}<-90 \%$, the difference in the water vapor pressure of wetPrf and radiosonde is greater than one order of magnitude. We used the absolute deviation of specific humidity and the relative error of water vapor in the comparison because although the absolute deviation of specific humidity has been used much more frequently in other studies, it includes the error of atmospheric pressure, so the comparison of the relative error only used the water vapor pressure itself. 

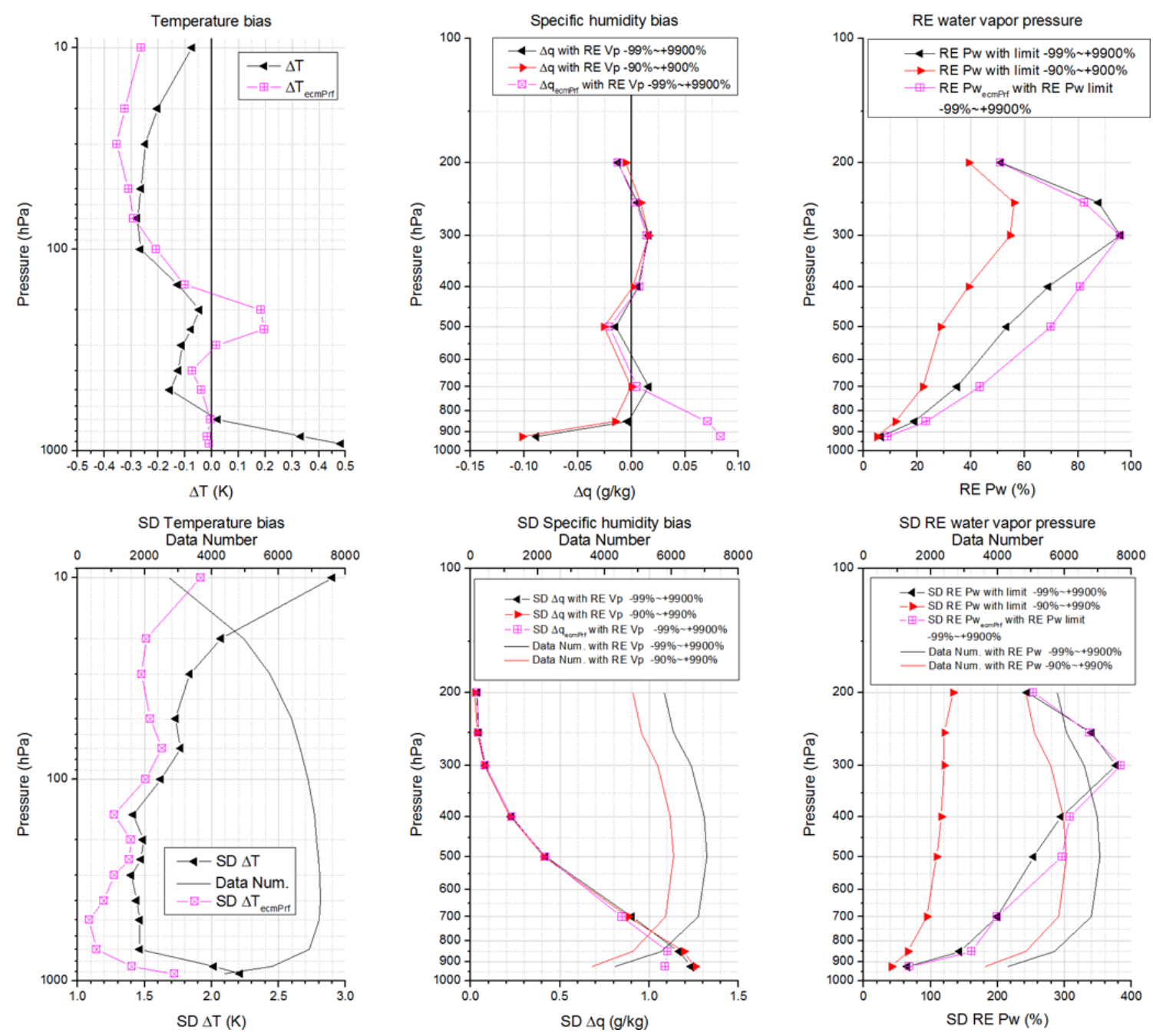

Fig. 2. Comparison of mean temperature bias, mean specific humidity bias, relative error of water vapor pressure, and their SDs. The purple curves show the results of the background ecmPrf, curves without symbols show the number of data points.

\section{Comparison results}

\subsection{Bias and relative error distribution}

A total of 7299 profiles matched globally from 2007 to 2010, including 93511 radiosonde temperature data points and 79403 dew-point depression data points. On average, a single profile included about 13 layers with temperature data points and 11 layers with humidity data points.

The left graphs in Fig. 2 show the mean temperature bias at each layer and their SDs. The mean temperature bias were all within $\pm 0.5 \mathrm{~K}$ in each layer. The global mean temperature bias of $925-10 \mathrm{hPa}$ was $-0.09 \mathrm{~K}$, with the SD of $1.72 \mathrm{~K}$. The wetPrf temperature was a bit higher than the radiosonde temperature in the layers below $700 \mathrm{hPa}$ (pressure larger than $700 \mathrm{hPa}$ ), and a bit lower in the layers above $700 \mathrm{hPa}$. The SD in the layers from $700 \mathrm{hPa}$ to $150 \mathrm{hPa}$ was within the range of $1.4-1.5 \mathrm{~K}$; the SD increased in the higher layers above
$100 \mathrm{hPa}$, with values of $2.07 \mathrm{~K}$ in the layer at $20 \mathrm{hPa}$, increasing rapidly to $2.90 \mathrm{~K}$ in the layer at $10 \mathrm{hPa}$. A large SD was also seen in the layers below $700 \mathrm{hPa}$, with a value of $2.21 \mathrm{~K}$ in the layer at $925 \mathrm{hPa}$.

The wetPrf water vapor pressure was much smaller compared to radiosonde in the layers above $200 \mathrm{hPa}$. Figure 3 shows the mean water vapor pressure profile of wetPrf, background and radiosonde. The wetPrf water vapor pressure was much more stable in the layers above $200 \mathrm{hPa}$, compared with radiosonde data. The radiosonde mean water vapor pressure showed no significant decrease in the layers above $200 \mathrm{hPa}$, which seemed to be incorrect. Therefore, the comparison of humidity was focused in the layers below $200 \mathrm{hPa}$. Due to extreme relative error of the water vapor pressure, which markedly affected the results, those profiles which contained such data points were removed from the comparison. Setting the limit of the relative error of water vapor pressure at $-99 \%$ to $+9900 \%$ (two orders of magnitude 

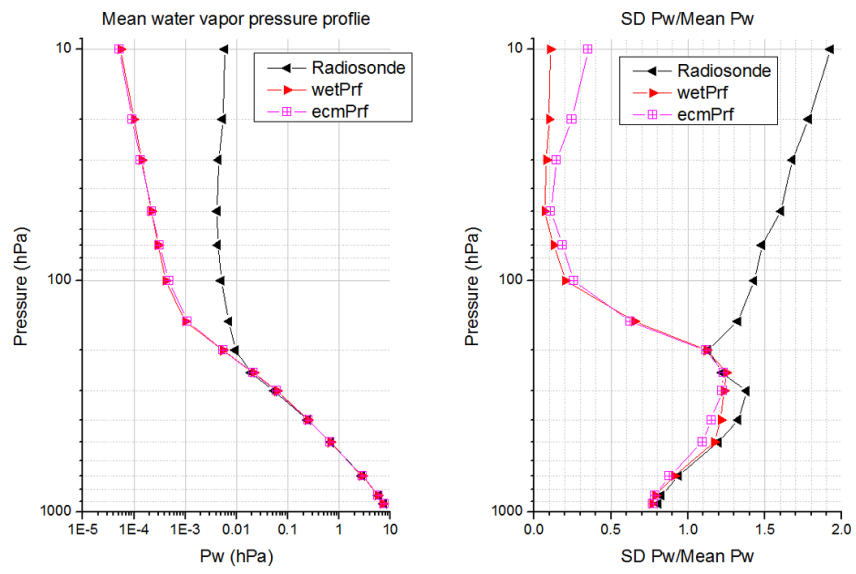

Fig. 3. Mean water vapor pressure profile of radiosonde, wetPrf, and the background ecmPrf.

difference), in the layers of $925-200 \mathrm{hPa}, 74$ data points out of the total of 49772 overstepped the limit, 74 profiles out of the total of 7299 were removed, leaving 7225 profiles. Setting the limit of the relative error of water vapor pressure at $-90 \%$ to $+900 \%$ (one order of magnitude difference), 1394 data points overstepped the limit, 6202 profiles remained, and 1097 profiles were removed. The comparison of specific humidity and water vapor pressure used the same samples. Although the data filtration slightly influenced the result of temperature comparison and refractivity comparison, it was not suitable to use the same filtration in these comparisons. Because, the temperature comparison and refractivity comparison were performed in the layers from $925 \mathrm{hPa}$ to $10 \mathrm{hPa}$, and there were too many data points which overstepped the limit in the layers above $200 \mathrm{hPa}$.

The middle graphs in Fig. 2 show the mean absolute deviation of specific humidity and their SDs. The global mean specific humidity bias at $925-200 \mathrm{hPa}$ was $-0.012 \mathrm{~g} \mathrm{~kg}^{-1}$ $\left(-0.006 \mathrm{~g} \mathrm{~kg}^{-1}\right)$ with the relative error limit of water vapor pressure $-90 \%$ to $+900 \%(-99 \%$ to $+9900 \%)$, and the SD was $0.666 \mathrm{~g} \mathrm{~kg}^{-1}\left(0.662 \mathrm{~g} \mathrm{~kg}^{-1}\right)$. The wetPrf specific humidity was smaller than radiosonde in near-ground layers, but the background specific humidity was larger. The wetPrf specific humidity was larger than the radiosonde specific humidity around the layer of $300 \mathrm{hPa}$. The right graphs in Fig. 2 show the mean relative error of water vapor pressure and their SDs. With the limit of $-90 \%$ to $+900 \%(-99 \%$ to $+9900 \%)$, the mean relative error in the layers of $925-200 \mathrm{hPa}$ was $+33.3 \%(+54.6 \%)$, and the SD was $107.5 \%(266.0 \%)$, respectively. The layers around $300 \mathrm{hPa}$ were more sensitive to the changes in relative error limit. Despite the large mean relative error, the mean absolute deviation was small.

The large mean relative error has relations with the distribution of the relative error and the function used to calculate the relative error. The negative relative error can only reach $-100 \%$, but the positive relative error could be much larger

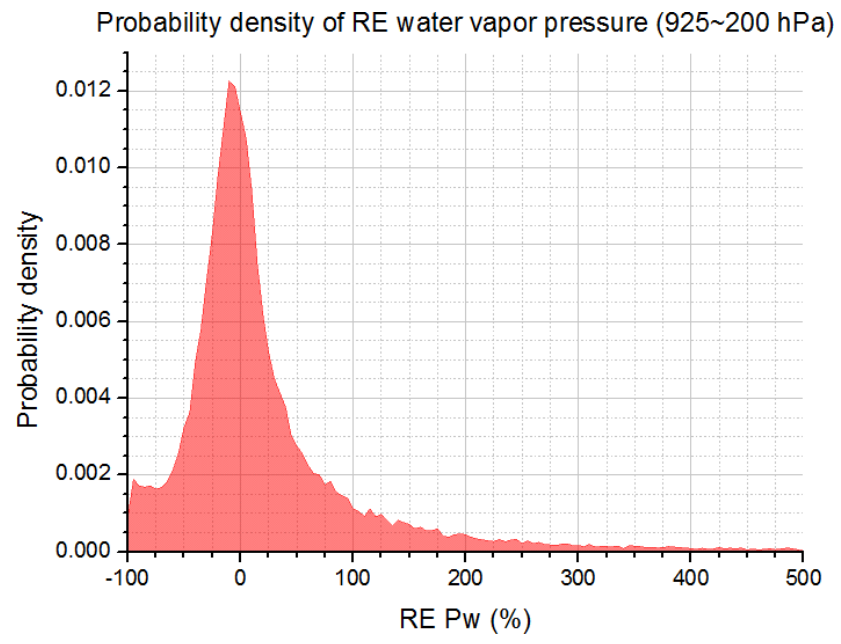

Fig. 4. Probability density of the relative error of water vapor pressure in the layers of 925 to $200 \mathrm{hPa}$.

than $+100 \%$. Figure 4 shows the probability density of the relative error of water vapor pressure in the layers of 925$200 \mathrm{hPa}$ without data filtration. Although the peak is located on the negative side, the large positive relative error is greater than the negative error, and the mean relative error is positive. As shown in the figure, the limit of $-90 \%$ to $+900 \%$ is representative.

Figure 5 shows the distribution of the relative error of water vapor pressure in the layers of $925-200 \mathrm{hPa}$ without data filtration. Similar to the results shown in Fig. 4, the peak is located on the negative side, but the large positive relative error is greater than the negative error. The relative error is much larger if the water vapor pressure value is lower, especially when the radiosonde water vapor pressure value is lower than $0.1 \mathrm{hPa}$. Taking into consideration the data points for which the radiosonde water vapor pressure is larger than $0.01 \mathrm{hPa} / 0.1 \mathrm{hPa}$, the mean relative error of water vapor pressure in the layers of $925-200 \mathrm{hPa}$ is $+26.9 \% /+12.4 \%$, with a relative error limit of $-99 \%$ to $+9900 \%$, while the mean relative error of water vapor pressure without any radiosonde water vapor pressure limit is $+54.6 \%$.

Despite of the the large relative error of water vapor pressure, the refractivity did not change markedly. Figure 6 shows the relative error of the refractivity from radio occultation observation (observed refractivity), the 1DVAR product wetPrf (retrieved refractivity), the background ecmPrf and the refractivity calculated from radiosonde, respectively. The large relative error of water vapor pressure had little effect on refractivity bias. The relative error of refractivity was within $\pm 1.6 \%$. Noticeable differences between observation and retrieval product were seen only in the layers below $700 \mathrm{hPa}$. The differences of refractivity between radio occultation observation and the background were also larger in this region. The retrieval process would reduce the mean bias and SD in these layers. 


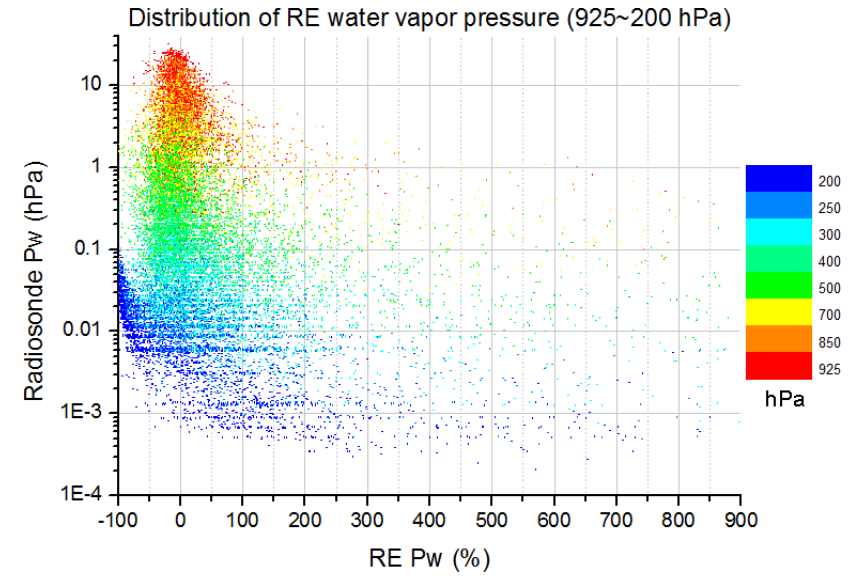

Fig. 5. Distribution of the relative error of water vapor pressure in the layers of 925 to $200 \mathrm{hPa}$.
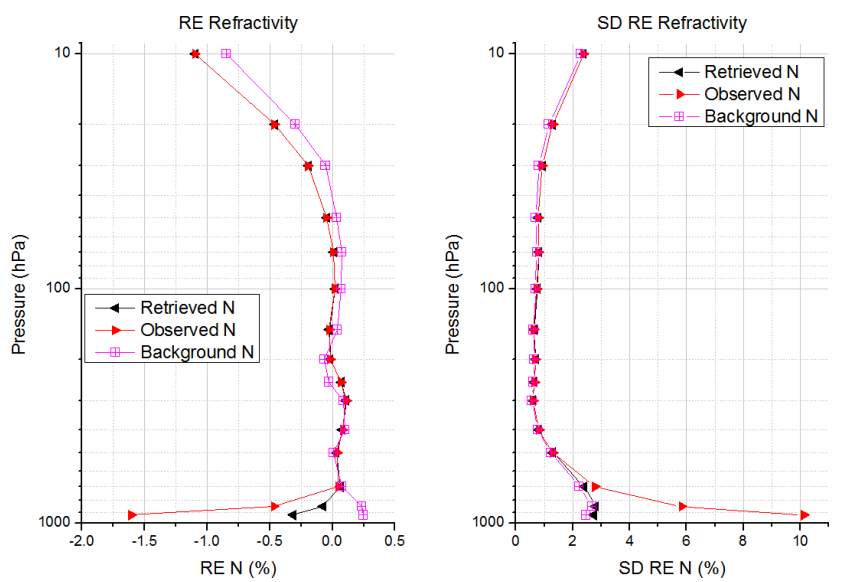

Fig. 6. Relative error and SD between the refractivity from the radio occultation observation, retrieval product wetPrf, background ecmPrf and the refractivity calculated from radiosonde data, respectively.

\subsection{Distribution of extreme relative error of water vapor pressure}

In this section, all 7299 profiles were used. Figure 7 shows the distribution of extreme relative error of water vapor pressure. The total number of matched water vapor data points in the layers of $925-200 \mathrm{hPa}$ is 49698 , of which four and 626 had a positive relative error larger than $+9900 \%$ and $+900 \%$, respectively. The peak was located in the layer at $300 \mathrm{hPa}$. There are mainly three types of cases. In the first case, the value of radiosonde water vapor pressure was extremely low in this layer but normal in the layers nearby. Usually, this low radiosonde water vapor pressure occurred in a single layer, so there would be a large positive relative error in this layer but normal in the layers nearby. The radiosonde water vapor pressure on the layer below could be $1000 \%$ higher than the value in these layers, and the value in the layer above could

\section{Distribution of the probability of extreme relative error $\mathrm{Pw}$}

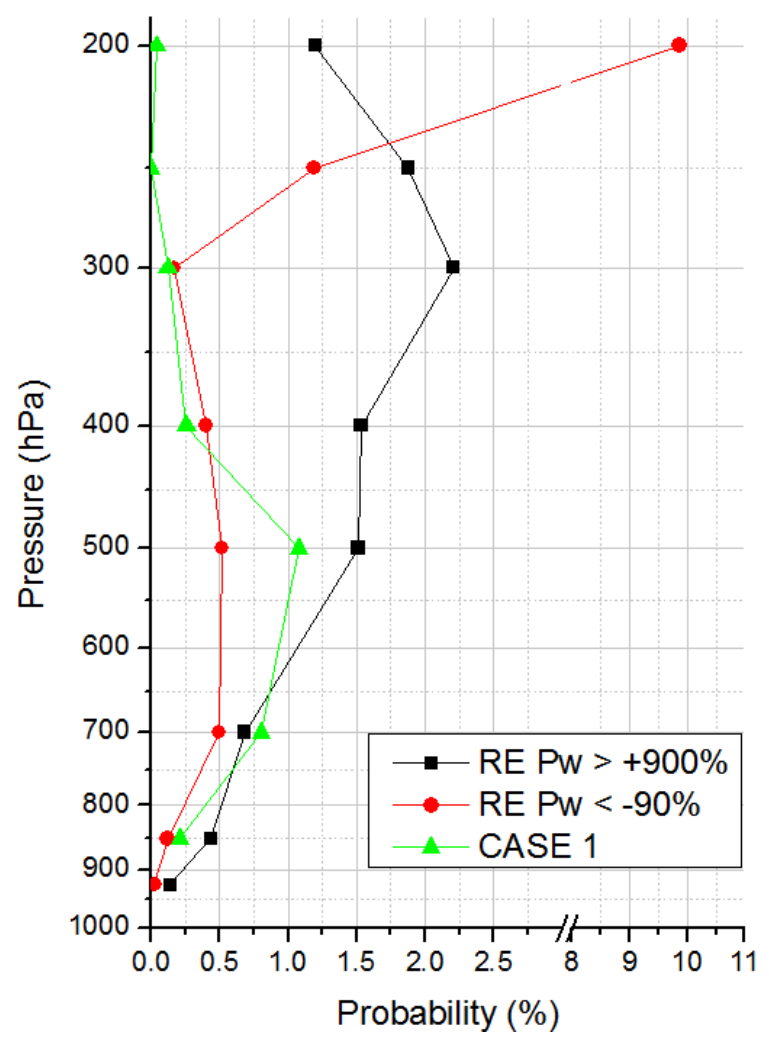

Fig. 7. Distribution of extreme relative error of water vapor pressure. The black curve shows the probability of data whose relative error of water vapor pressure is larger than $+900 \%$, the red curve shows the probability of data whose relative error of water vapor pressure is smaller than $-90 \%$. The green curve shows the probability of case 1 described in the paper.

be $200 \%$ higher. Among the total of 49698 data points, 172 agreed with this rule; there were only 10 of them whose relative error was less than $100 \%$. In all, 61 of them had positive relative error larger than $+900 \%$, representing only about $10 \%$ of all the extreme positive relative errors. The peak was located at $500 \mathrm{hPa}$, which was also different from the peak at $300 \mathrm{hPa}$ considering all the data points. Therefore, the first case would not include a large number of data points. In the second case, the radiosonde profile had a much larger water vapor pressure decrease rate than wetPrf. Sometimes the water vapor pressure of radiosonde decreased much faster or began to decrease rapidly in lower layers compared with wetPrf. Usually, the second case occurred in the layer of 500 $200 \mathrm{hPa}$. The peak was located at $300 \mathrm{hPa}$, where there was also the peak of positive absolute deviation and relative error. Most data points with extreme positive relative error of water vapor pressure belonged to the second case. In the third case, wetPrf's water vapor pressure was systematically larger than radiosonde. Usually, this case occurred in the layer below 
Table 2. Mean bias of different radiosonde types between wetPrf and radiosonde ${ }^{\mathrm{a}}$.

\begin{tabular}{|c|c|c|c|c|c|c|c|}
\hline \multirow[b]{2}{*}{ Type } & \multirow[b]{2}{*}{$\begin{array}{l}\Delta T \\
(\mathrm{~K})\end{array}$} & \multirow[b]{2}{*}{$\begin{array}{r}\mathrm{SD} \Delta T \\
(\mathrm{~K})\end{array}$} & \multicolumn{4}{|c|}{$925-200 \mathrm{hPa}$} & \multirow[b]{2}{*}{$\begin{array}{l}\text { Num. of } \\
\text { profiles }\end{array}$} \\
\hline & & & $\begin{array}{r}\Delta q \\
\left(\mathrm{~g} \mathrm{~kg}^{-1}\right)\end{array}$ & $\begin{array}{c}\mathrm{SD} \Delta q \\
\left(\mathrm{~g} \mathrm{~kg}^{-1}\right)\end{array}$ & $\operatorname{RE} P_{\mathrm{W}}$ & $\begin{array}{r}\text { SD RE } \\
P_{\mathrm{w}}\end{array}$ & \\
\hline CHINA GTS1 1680 MHZ & -0.070 & 1.670 & 0.063 & 0.687 & $60.5 \%$ & $143.5 \%$ & $553 / 450$ \\
\hline CHINA GZZ-2 403 MHZ & -0.104 & 1.667 & 0.084 & 0.688 & $40.3 \%$ & $113.3 \%$ & $203 / 168$ \\
\hline JAPAN MEISEI RSII-91 RH CORRECTION & 0.003 & 1.583 & -0.058 & 0.956 & $32.9 \%$ & $117.9 \%$ & $139 / 135$ \\
\hline RUSSIA/USSR MRZ-3A & -0.330 & 1.757 & -0.043 & 0.521 & $-7.6 \%$ & $56.8 \%$ & $1542 / 1155$ \\
\hline VIZ/SIPPICAN B2 1492-540 NWS 1680 MHZ & 0.105 & 1.719 & 0.003 & 0.699 & $29.7 \%$ & $106.6 \%$ & $380 / 319$ \\
\hline VIZ/SIPPICAN MICROSONDE MKIIA GPS & 0.176 & 1.541 & -0.027 & 0.655 & $43.5 \%$ & $118.6 \%$ & $613 / 474$ \\
\hline VAISALA RS80 & -0.002 & 1.560 & -0.006 & 0.647 & $45.6 \%$ & $111.8 \%$ & $2288 / 2080$ \\
\hline VAISALA RS92 & 0.024 & 1.521 & -0.024 & 0.662 & $59.6 \%$ & $124.5 \%$ & $343 / 313$ \\
\hline
\end{tabular}

${ }^{a}$ Equations (7)-(9) were used. The water vapor pressure relative error limit was $-90 \%$ to $900 \%$. ${ }^{\text {b }}$ The first number was a profile number of temperature comparison and the second number was a profile number of humidity comparison.

$500 \mathrm{hPa}$. The number of the third case was small compared to the second case.

In all, 70 out of the total 49698 data points in the layers of 925-200 hPa had a negative relative error larger than $-99 \%$ and 768 were larger than $-90 \%$. The peak was located at $200 \mathrm{hPa}$, due to the systematic humidity bias in layers above $200 \mathrm{hPa}$. The number of extreme negative relative errors was much smaller compared with the extreme positive ones in the layers below $300 \mathrm{hPa}$. Most of extreme negative relative error in lower layers belonged to this case, in which the value of wetPrf water vapor pressure was extremely low in the layer but normal in lower and higher layers. The extremely low water vapor pressure seemed to be inconsistent with the real atmosphere (e.g., in the profile of C003.2008.287.11.55, the water vapor pressure was $1 \times 10^{-6} \mathrm{hPa}$ at the height of $5.7-6.3 \mathrm{~km}$ ), and the quality control process did not eliminate these data points. A single profile could have more than one layer of the extremely low water vapor pressure. About $7.6 \%$ of the wetPrf profiles included at least one layer of extremely low water vapor pressure, the mean total thickness of the extremely low water vapor pressure layer in a single profile was about $414 \mathrm{~m}$. The majority of this phenomenon occurred in layers below $10 \mathrm{~km}$, especially in the altitude region of 2-8 km, but it also occurred in layers above $10 \mathrm{~km}$. Figure 8 shows the distribution of the probability of the profile which included extremely low water vapor pressure (less than $2 \times 10^{-6} \mathrm{hPa}$ ). Most of the extremely low water vapor pressure occurred below $10 \mathrm{~km}$ and were located in the latitude region of -45 to $45^{\circ}$, especially in subtropical zone, and most of the extremely low water vapor pressure occurred above $10 \mathrm{~km}$ and were located in the latitude region of -90 to $-45^{\circ}$ and 45 to $90^{\circ}$. This phenomenon was often concomitant with smaller observed refractivity, smaller retrieved refractivity and higher retrieved temperature than those of background. If the observed refractivity was much smaller than background, the 1DVAR process trended to generate lower water vapor pressure and higher temperature. If the refractivity bias was large enough, the retrieved water vapor pressure might be extremely low or even negative. But things were different in near-ground layers, statistics indicated that the extremely low water vapor pressure phenomenon could be concomitant with larger observed and retrieved refractivity than background when altitude was less than $1 \mathrm{~km}$, and lower temperature than background when altitude was less than $2 \mathrm{~km}$. Overall, the large value regions in Fig. 8 indicated that large negative refractivity bias in COSMIC observation and background ECMWF analysis occurred frequently in those regions.

We have developed an 1DVAR retrieval algorithm which generated temperature and specific humidity profiles using COSMIC's refractivity profile and ECMWF analysis. Temperature profile and humidity profile were retrieved from the observed refractivity profile, and the background was ecmPrf data. Our 1DVAR process also generated the extremely low water vapor pressure data points. The results showed that the error covariance matrixes had significantly influenced on the retrieval profiles. The extremely low water vapor pressure could be abated if the the error covariance matrixes were adjusted properly. However, this would make the retrieved water vapor pressure profile closer to the background, and the temperature profile was also affected.

\subsection{Comparison of the results with different radiosonde types}

COSMIC provides global coverage of radio occultation observations and can be used to assess other observations or model results (Sun et al., 2010; He et al., 2009; Ho et al., 2010). Here, we present a comparison of COSMIC products with eight different radiosonde types. As many of the radiosonde types are used in limited regions, this comparison can be used to determine the bias of COSMIC in these regions if we use radiosonde data as benchmarks. The radiosonde types included in the comparison were GTS1 and GZZ-2 (China), MEISEI (Japan), MRZ-3A (Russia), 


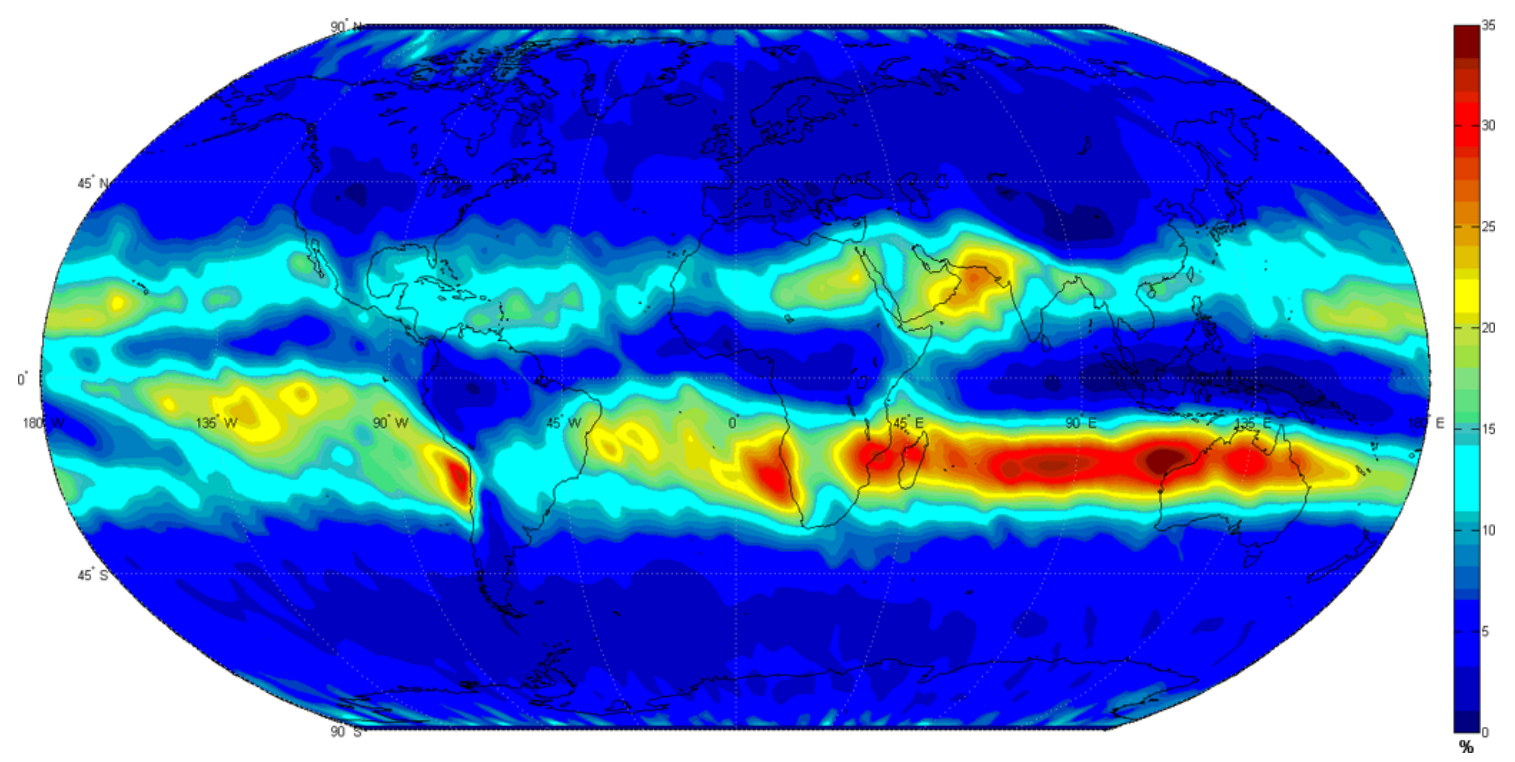

Fig. 8. Distribution of the probability of the profiles which contains extremely small humidity data $\left(P_{\mathrm{W}}<2 \times 10^{-6} \mathrm{hPa}\right)$. The grid is $5^{\circ} \times 5^{\circ}$.

two types of VIZ (USA), and VAISALA RS80 and RS92. However, there was a problem in that the wetPrf product is produced through an 1DVAR retrieval process using the ECMWF analysis as the background, and it is therefore affected by the different background errors in different regions. Therefore, the comparison is more likely to indicate how the wetPrf data match those from certain types of radiosonde in certain regions. In this comparison, the radiosonde data were set as the benchmarks. It was assumed that the error of a certain kind of radiosonde type would remain the same in different regions. The method used was the same as that in the comparisons described above (Eqs. 7-9). An inverse process is needed to determine the differences among different radiosonde types. For example, a lower curve in mean temperature bias figure indicates that the radiosonde type will yield higher temperature data compared with the other types.

The comparison results are shown in Fig. 9 and the mean bias results are shown in Table 2. The left graphs in Fig. 9 show the results of temperature comparison. Most of these radiosonde types showed similar performance. However, MRZ-3A was unique, in that it had much higher temperature compared with the other radiosonde types, especially at layers around $300 \mathrm{hPa}$. Conversely, VIZ/SIPPICAN MICROSONDE MKIIA GPS had lower temperature than others. The results indicated that the temperatures of the two radiosonde types used in China were slightly higher than those of the other radiosonde types. GTS1 showed better performance than GZZ-2, and GZZ-2 had larger SD at higher layers than the other types if the error of COSMIC product remained the same in different regions.

The middle graphs in Fig. 9 show the absolute deviation of specific humidity in layers from $925 \mathrm{hPa}$ to $200 \mathrm{hPa}$. MRZ-3A and JAPAN MEISEI RSII-91RH CORRECTION had larger value in layers above $700 \mathrm{hPa}$ compared to the other types. In the layers below $850 \mathrm{hPa}$, VIZ/SIPPICAN MICROSONDE MKIIA GPS had the largest positive bias, but in other layers its bias was small. The two radiosonde types used in China had much smaller specific humidity in layers below $500 \mathrm{hPa}$. The graphs on the right in Fig. 9 show the relative error of water vapor pressure in layers from $925 \mathrm{hPa}$ to $200 \mathrm{hPa}$. MRZ-3A was still unique, it had negative mean relative error while the others had positive mean relative error. GZZ-2 showed similar performance to the others. However, GTS1 still had much lower water vapor pressure values than the others, and its SD was the largest.

\subsection{Influence of background data}

wetPrf is the COSMIC 1DVAR retrieval product which uses the ECMWF analysis as the background, and it is therefore affected by the background. Figure 10 shows the relative error between observed, background and retrieved refractivity and the refractivity calculated from radiosonde, respectively. The same comparison method as that in the comparisons described above was used, the radiosonde was set as the benchmark (Eq. 10). The same data filtration was used as above, the limit of the relative error of water vapor pressure was $-90 \%$ to $+900 \%$. The observed refractivity of COSMIC in the region of China was normal or slightly smaller than in the others in the layers below $500 \mathrm{hPa}$. After the retrieval process, the mean refractivity became much smaller than the other types. This phenomenon may have been due to the background error if the retrieval algorithm was stable globally. The refractivity data of background ecmPrf in China had much larger bias from radiosonde than in the other regions, and the refractivity in this region was much smaller 

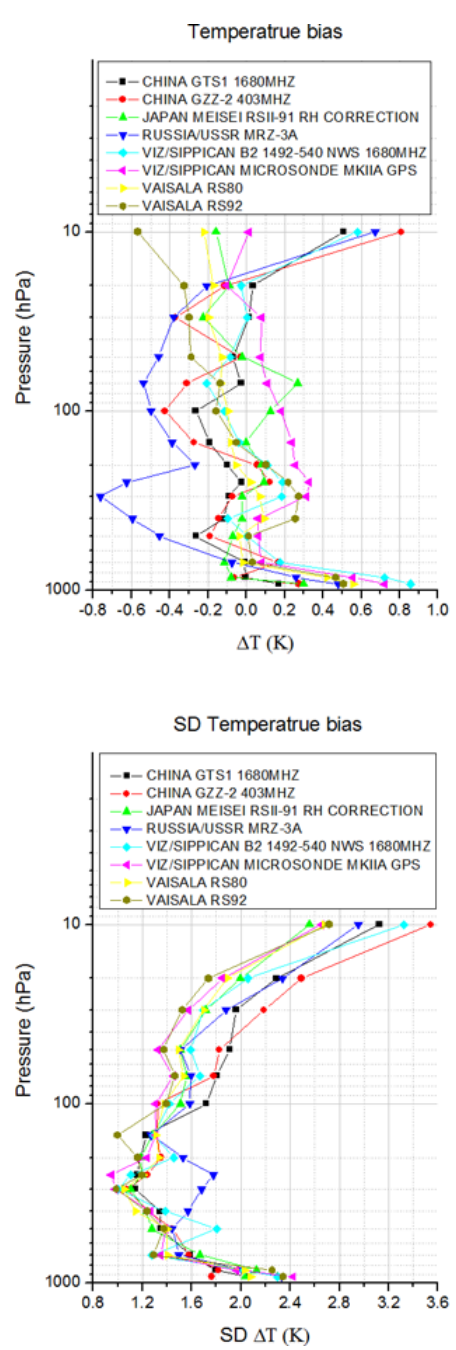
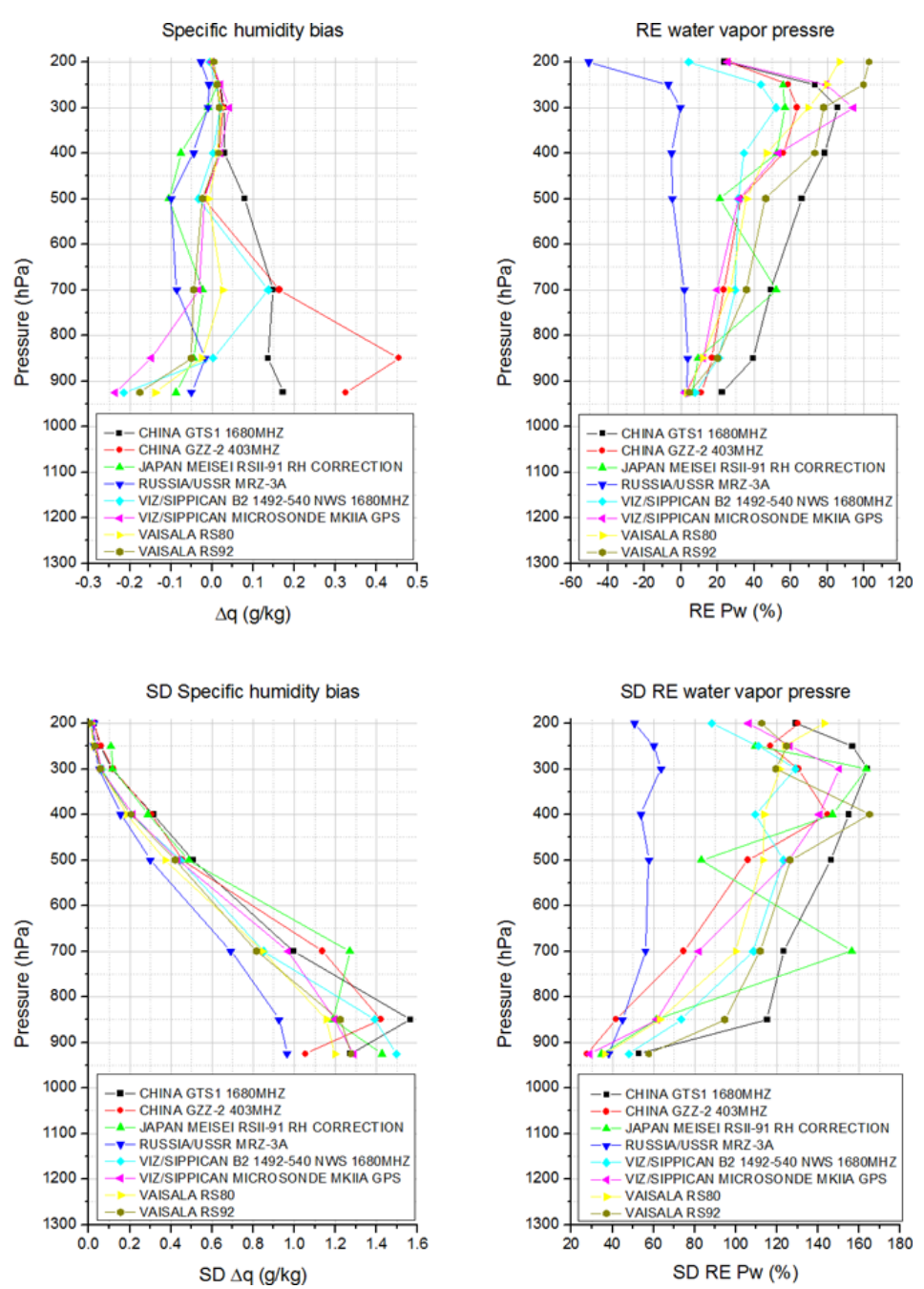

Fig. 9. Differences in mean temperature bias, mean specific humidity bias, relative error of water vapor pressure and their SDs between COSMIC and different radiosonde types. Radiosonde data is the benchmark.

than that in the other regions. As shown in the figure, the retrieved refractivity was much more similar to the background than to the observation, and so were the SDs. The error of wetPrf data was affected by the background error, and the background error showed considerable differences between different regions. The figure of the relative error of refractivity is similar to the figure of the specific humidity bias in Sect. 3.3.

Although some studies have indicated that COSMIC is suitable as a benchmark (Sun et al., 2010; He et al., 2009; Ho et al., 2010), we feel that the retrieval product could be used as benchmark if no better method is available, or if the precision requirement is not particularly strict, or if the background error is well known. As the refractivity observation is not affected by background, the observed refractivity profile is more suitable to be used as a benchmark than the 1DVAR retrieval product. There were noticeable differences between different versions of the wetPrf data, and improvement of the retrieval process may reduce the bias.

\section{Conclusions}

As the collocation mismatch has an impact on the comparison standard deviations (Sun et al., 2010), we collected samples for the four years from 2007 to 2010 to obtain sufficient data with stricter matching rules used than in previous studies so as to obtain more accurate results. The matching criteria were $1 \mathrm{~h}$ and $100 \mathrm{~km}$. The COSMIC 1DVAR product wetPrf showed good atmospheric temperature data quality. The global mean temperature bias at $925-10 \mathrm{hPa}$ was $-0.09 \mathrm{~K}$, with a standard deviation of $1.72 \mathrm{~K}$. The wetPrf temperature was slightly higher than radiosonde below the layer of $700 \mathrm{hPa}$ and was slightly lower above. The radiosonde humidity was significantly larger than wetPrf and background ecmPrf above the layer of $200 \mathrm{hPa}$. As the radiosonde humidity data were not reliable above the layer of $200 \mathrm{hPa}$, the comparison of humidity was focused in the layers below $200 \mathrm{hPa}$. The global mean specific humidity bias at 925 $200 \mathrm{hPa}$ was about $-0.012 \mathrm{~g} \mathrm{~kg}^{-1}$, with a standard deviation 

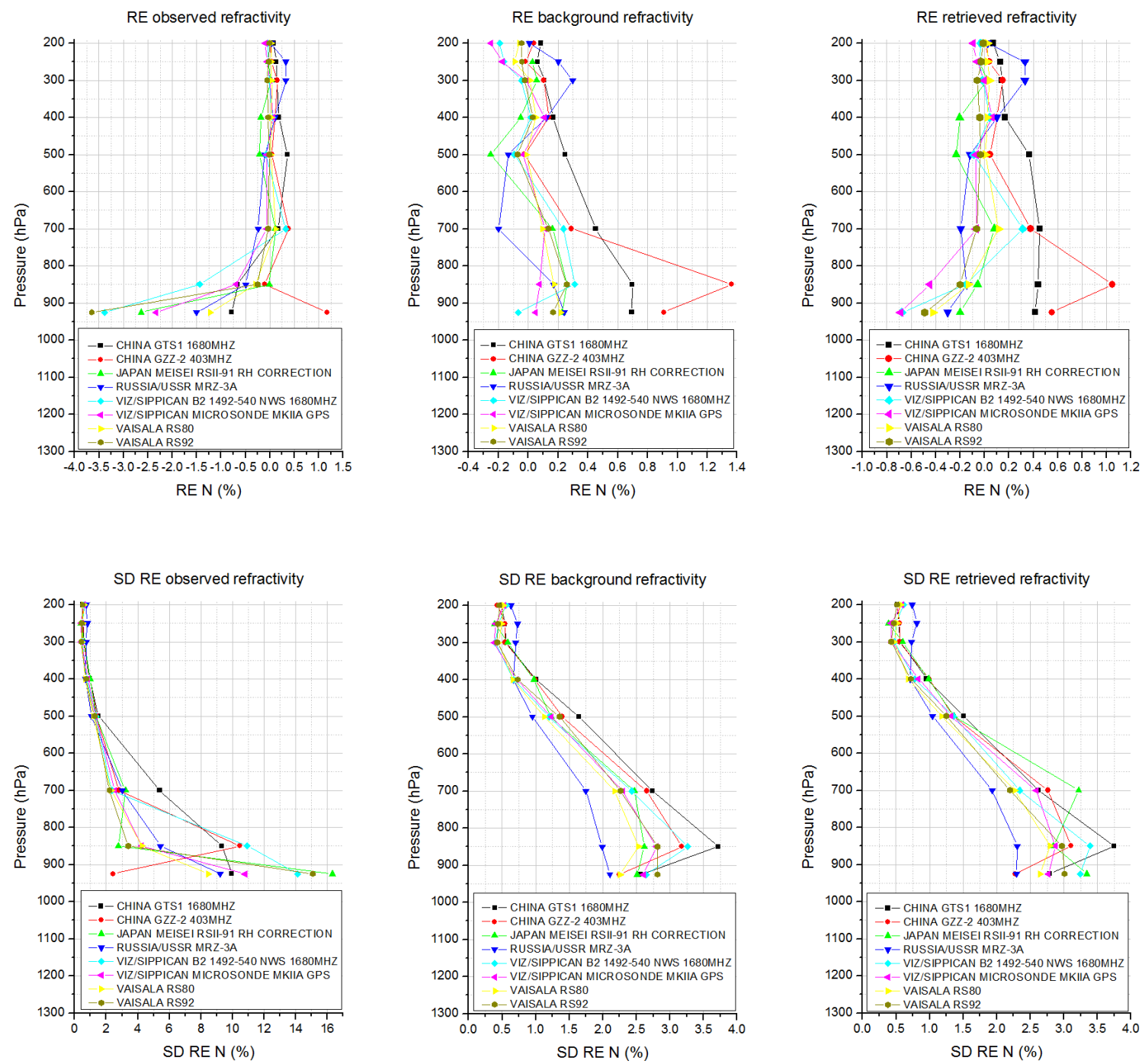

Fig. 10. Relative error and SD between the refractivity of different radiosonde types and the refractivity from the 1DVAR product wetPrf, radio occultation observation, and background, respectively.

of about $0.666 \mathrm{~g} \mathrm{~kg}^{-1}$. The mean absolute deviation of specific humidity was small, but the relative error was significantly large. The mean relative error of water vapor pressure in the pressure range of $925-200 \mathrm{hPa}$ was about $+33 \%$ to $+55 \%$, depending on the different data filtration used in this paper. The peak of positive relative error was located at about $300 \mathrm{hPa}$. The large relative error might have been due to the extremely small humidity data of radiosonde or wetPrf, or to the differences in the rate of decrease in humidity. The quality control process of COSMIC failed to detect these abnormal extremely small humidity data. The majority of this phenomenon occurred in subtropical zone. The extremely small humidity data were generated by IDVAR process when the observed refractivity was significantly smaller than background. The large relative error of water vapor pressure had little effect on refractivity. The 1DVAR retrieval process would reduce the refractivity bias and the standard deviation in near-ground layers. The differences between retrieved refractivity and observation were small on layers above $200 \mathrm{hPa}$.

Comparison of COSMIC with different radiosonde types demonstrated its ability to assess other observation data. All of the eight radiosonde types showed good temperature agreement with wetPrf. The performance of MRZ-3A from Russia was unique, which was probably due to the high latitude region in which the radiosonde equipment is located. The temperature of the two Chinese radiosonde types performed well. However, the humidity of the two Chinese radiosonde types were significantly smaller compared with the other types. One possible reason for this is the ECMWF analysis data which were used as the background. The refractivity bias in the region of China between ECMWF analysis and radiosonde were much larger than the other regions, similar to the results of the humidity comparison between wetPrf and 
radiosonde. The retrieved refractivity was much more similar to the background than to the observation in near-ground layers, and the retrieved refractivity was much closer to the observation in higher layers. The COSMIC product wetPrf could be used as a benchmark if the precision requirement is not strict, or if no better alternative is available, or the background error is well known. Another problem is that the COSMIC data coverage is still insufficient, an improvement must await the launch of COSMIC II.

Acknowledgements. The authors are grateful to the COSMIC Data Analysis and Archive Center (CDAAC) and Integrated Global Radiosonde Archive (IGRA) for providing their data. This work was funded by the National Natural Science Foundation of China (41075011) and Special Fund for Meteorology Research in the Public Interest (GYHY201006037).

Edited by: J.-P. Pommereau

\section{References}

Christy, J. R. and Norris, W. B.: Discontinuity issues with radiosonde and satellite temperatures in the Australian region 1979-2006, J. Atmos. Ocean. Tech., 26, 508-522, doi:10.1175/2008JTECHA1126.1, 2009.

Fu, E.-J., Zhang, K.-F., Ka-yea, M., Xu, X.-H., John, M., Anthony, R., Gary, W., and Yuriy, K.: Assessing COSMIC GPS radio occultation derived atmospheric parameters using Australian radiosonde network data, Procedia Earth and Planetary Science, 1, 1054-1059, 2009.

Goff, J. A.: Saturation pressure of water on the new Kelvin scale, T. Am. Soc., Heating Air-Cond. Eng., 63, 347-354, 1957.

Hajj, G. A., Lee, L. C., Pi, X., Romans, L. J., Schreiner, W. S., Straus, P. R., and Wang, C.: COSMIC GPS ionospheric sensing and space weather, Terr. Atmos. Ocean. Sci., 11, 235-272, 2000.

Hajj, G. A., Ao, C. O., Iijima, B. A., Kuang, D., Kursinski, E. R., Mannucci, A. J., Meehan, T. K., Romans, L. J., de la Torre Juarez, M., and Yunck, T. P: CHAMP and SAC-C atmospheric results and intercomparisons, J. Geophys. Res., 109, D06109, doi:10.1029/2003JD003909, 2004.

He, W., Ho, S.-P., Chen, H., Zhou, X., Hunt, D., and Kuo, Y.-H.: Assessment of radiosonde temperature measurements in the upper troposphere and lower stratosphere using COSMIC radio occultation data, Geophys. Res. Lett., 36, L17807, doi:10.1029/2009GL038712, 2009.

Ho, S.-P., Zhou, X., Kuo, Y.-H., Hunt, D., and Wang, J.-H.: Global evaluation of radiosonde water vapor wystematic biases using GPS radio occultation from COSMIC and ECMWF analysis, Remote Sens., 2, 1320-1330, doi:10.3390/rs2051320, 2010.

Kishore, P., Namboothiri, S. P., Jiang, J. H., Sivakumar, V., and Igarashi, K.: Global temperature estimates in the troposphere and stratosphere: a validation study of COSMIC/FORMOSAT-3 measurements, Atmos. Chem. Phys., 9, 897-908, doi:10.5194/acp-9-897-2009, 2009.

Kuo, Y.-H., Wee, T.-K., Sokolovskiy, S., Rocken, C., Schreiner, W., Hunt, D., and Anthes, R. A.: Inversion and error estimation of GPS radio occultation data, J. Meteorol. Soc. Jpn., 82, 507-531, doi:10.2151/jmsj.2004.507, 2004.
Kuo, Y.-H., Schreiner, W. S., Wang, J., Rossiter, D. L., and Zhang, Y.: Comparison of GPS radio occultation soundings with radiosondes, Geophys. Res. Lett., 32, L05817, doi:10.1029/2004GL021443, 2005.

Kursinski, E. R., Hajj, G. A., Bertiger, W. I., Leroy, S. S., Meehan, T. K., Romans, L. J., Schofield, J. T., Mccleese, D. J., Melbourne, W. G., Thornton, C. L., Yunck, T. P., Eyre, J. R., and Nagatani, R. N.: Initial results of radio occultation observations of Earth's atmosphere using the Global Positioning System, Science, 271, 1107-1110, doi:10.1126/science.271.5252.1107, 1996.

Kursinski, E. R., Hajj, G. A., Leroy, S. S., and Herman, B.: The GPS Radio Occultation Technique, Terrestrial, Atmos. Ocean. Sci., 11, 53-114, 2000.

Luers, J. K. and Eskridge, R. E.: Use of radiosonde temperature data in climate studies, J. Climate, 11, 1002-1019, 1998.

Miloshevich, L. M., Vömel, H., Whiteman, D. N., Lesht, B. M., Schmidlin, F. J., and Russo, F.: Absolute accuracy of water vapor measurements from six operational radiosonde types launched during AWEX-G and implications for AIRS validation, J. Geophys. Res., 111, D09S10, doi:10.1029/2005JD006083, 2006.

Rocken, C., Anthes, R., Exner, M., Hunt, D., Sokolovskiy, S., Ware, R., Gorbunov, M., Schreiner, W., Feng, D., Herman, B., Kuo, Y.H., and Zou, X.: Analysis and validation of GPS/MET data in the neutral atmosphere, J. Geophys. Res., 102, 29849-29866, 1997.

Seidel, D. J., Sun, B., Pettey, M., and Reale, A.: Global radiosonde balloon drift statistics, J. Geophys. Res., 116, D07102, doi:10.1029/2010JD014891, 2011.

Steiner, A. K., Kirchengast, G., and Ladreiter, H. P.: Inversion, error analysis, and validation of GPS/MET occultation data, Ann. Geophys., 17, 122-138, doi:10.1007/s00585-999-0122-5, 1999.

Soden, B. J. and Lanzante, J. R.: An assessment of satellite and radiosonde climatologies of upper tropospheric water vapor, J. Climate, 9, 1235-1250, doi:10.1175/15200442(1996)009; 1235:AAOSAR;2.0.CO;2, 1996.

Sun, B., Reale, A., Seidel, D. J., and Hunt, D. C.: Comparing radiosonde and COSMIC atmospheric profile data to quantify differences among radiosonde types and the effects of imperfect collocation on comparison statistics, J. Geophys. Res., 115, D23104, doi:10.1029/2010JD014457, 2010.

Wang, J. and Zhang, L.: Systematic errors in global radiosonde precipitable water data from comparisons with ground-based GPS measurements, J. Climate, 21, 2218-2238, doi:10.1175/2007JCLI1944.1, 2008.

Wang, J., Carlson, D. J., Parsons, D. B., Hock, T. F., Lauritsen, D., Cole, H. L., Beierle, K., and Chamberlain, E.: Performance of operational radiosonde humidity sensors in direct comparison with a chilled mirror dew-point hygrometer and its climate implication, Geophys. Res. Lett., 30, 1860, doi:10.1029/2003GL016985, 2003.

Ware, R., Exner, M., Feng, D., Gorbunov, M., Hardy, K., Herman, B., Kuo, Y., Meehan, T., Melbourne, W., Rocken, C., Schreiner, W., Sokolovskiy, S., Solheim, F., Zou, X., Anthes, R., Businger, S., and Trenberth, K.: GPS sounding of the atmosphere from Low Earth Orbit: Preliminary results, B. Am. Meteorol. Soc., 77, 1940, doi:10.1175/1520-0477(1996)077;0019:GSOTAF ¿2.0.CO;2, 1996.

Yunck, T. P., Liu, C., and Ware, R.: A history of GPS sounding, Terr. Atmos. Ocean. Sci., 11, 1-20, 2000. 